\title{
Relationship between the effects of food on the pharmacokinetics of oral antineoplastic drugs and their physicochemical properties
}

\author{
Fukiko Omachi', Masaki Kaneko ${ }^{1}$, Ryosuke lijima ${ }^{2}$, Machiko Watanabe ${ }^{1}$ and Fumio Itagaki ${ }^{{ }^{*}}$ (D)
}

\begin{abstract}
Background: Food is known to affect drug absorption by delaying gastric emptying time, altering gastrointestinal $\mathrm{pH}$, stimulating bile flow, increasing splanchnic blood flow, or physically interacting with drugs. Although food is known to affect the pharmacokinetics of oral antineoplastic drugs, the relationship between the effects of food and the physicochemical properties of drugs remains unclear.

Methods: In this study, we surveyed the literature on three kinds of pharmacokinetic changes, AUC ratio, $C_{\max }$ ratio and $T_{\max }$ ratio, in the fasted and fed state for 72 oral antineoplastic drugs that were listed on the drug price standard in May 2018 in Japan. We further predicted the physicochemical properties from the 2D chemical structure of the antineoplastic drugs using in silico predictions.

Results: As a result of analyzing the relationship between the effects of food and physicochemical properties, we found that compounds that show increased absorption in the fed state had higher logP and lower solubility in fasted-state simulated intestinal fluid (FaSSIF). However, compounds with delayed absorption had higher solubility in FaSSIF. Furthermore, as a result of decision tree analysis, it was classified as AUC increase with $\log P \geq 4.34$. We found that an AUC increase in the fed state did not occur with compounds with low lipid solubilities $(\log P<1.59)$. From these results, it is predicted that 7 compounds out of the 24 compounds for which the effects of food are unknown are at risk for increased absorption in the fed state and that no increase in absorption would occur in 13 compounds.

Conclusion: In this study, we found that drugs that will show increased absorption in the fed state and drugs for which absorption is not dependent on food can generally be predicted by logP. These results suggest that logP can be a useful parameter for predicting the effects of food on drug absorption.
\end{abstract}

Keywords: Food effects, Oral antineoplastic drugs, Pharmacokinetics, Physicochemical properties, In silico

\section{Background}

Food is well known to affect drug absorption by delaying gastric emptying time, altering gastrointestinal $\mathrm{pH}$, stimulating bile flow, increasing splanchnic blood flow, or physically interacting with drugs [1-3]. Furthermore, different foods, based on factors such as nutritional composition (high-protein, carbohydrate-rich, or high-fat meals), calorie

\footnotetext{
* Correspondence: f-itaga@pharm.teikyo-u.ac.jp

${ }^{1}$ Department of Clinical \& Pharmaceutical Sciences, Faculty of Pharma Science, Teikyo University, 2-11-1, Kaga, Itabashi-ku, Tokyo 173-8605, Japan Full list of author information is available at the end of the article
}

content (low vs high calorie meals), volume, temperature and fluid ingestion, have distinct influences on the transit time, luminal dissolution, permeability and bioavailability of the drug product [4].

The Biopharmaceutics Classification System (BCS) is a scientific framework for classifying drug substances based on their aqueous solubility and intestinal permeability [5]. According to the BCS, drug substances are classified as four categories based on their solubility and intestinal permeability. Fisher et al. reported that drug-food interactions could generally be

(C) The Author(s). 2019 Open Access This article is distributed under the terms of the Creative Commons Attribution 4.0 International License (http://creativecommons.org/licenses/by/4.0/), which permits unrestricted use, distribution, and 
predicted based on the BCS class [6]. Class 1 drugs with high solubility/high permeability; high-fat meal will have no significant effect on drug bioavailability, Class 2 drugs with low solubility/high permeability; high-fat meal will increase drug bioavailability, Class 3 drugs with high solubility/low permeability; high-fat meal will decrease drug bioavailability, Class 4 drugs with low solubility-low permeability; it is difficult to predict what will occur [6, 7]. $\mathrm{Gu} \mathrm{CH}$ et al. further improved the prediction of food effects by classifying drugs based on solubility, permeability and dose of a compound [8]. Although they analyzed 90 marketed compounds, only one oral antineoplastic drug was included in their models.

The number of oral antineoplastic drugs approved for manufacture in Japan has been substantially increasing [9]. In particular, remarkable increases in molecular target drugs, including many drugs affected by food, have occurred in recent years [10]. There are many drugs for which dietary conditions are defined in the usages described in the package inserts [11]. On the other hand, oral antineoplastic drugs that are not molecular target drugs include many drugs for which dietary conditions are not defined in the usage instructions. Since the therapeutic range and the toxic range are in close proximity for oral antineoplastic drugs, the effects of food must be considered when evaluating their varying pharmacokinetics. Although it is already known that food may affect the pharmacokinetics of oral antineoplastic drugs [12-14], the relationship between the effects of food and the physicochemical properties of the drugs remains unclear.

In this study, we review the pharmacokinetic changes caused by food in oral antineoplastic drugs and evaluate their relevance to the physicochemical properties of antineoplastic drugs by in silico predictions. In addition, we predicted the pharmacokinetic changes in drugs for which the effects of food are unknown using the physicochemical properties as indicators.

\section{Methods}

\section{Investigation of oral antineoplastic drugs}

We surveyed the literature on three kinds of pharmacokinetic changes, including the area under the curve of the drug concentration-time profile (AUC) ratio, the maximum serum concentration $\left(\mathrm{C}_{\max }\right)$ ratio, and the time at which $C_{\max }$ is observed $\left(\mathrm{T}_{\max }\right)$ ratio, in the fasted and fed state for 72 oral antineoplastic drugs that were listed on the drug price standard in May 2018 in Japan [15]. For drugs without ratio data in the literature, ratios were calculated from the medians or averages of the AUC, $C_{\max }$ and $T_{\max }$ values in the fasted or fed state. In addition, for drugs with data from several clinical trials, we selected data from high-fat meals when several data on meals were available and the closest data to those of the usage approved in Japan when data from several dosages and administration techniques were available. We analyzed the distributions of the AUC ratio, $\mathrm{C}_{\max }$ ratio and $\mathrm{T}_{\max }$ ratio and the relationships between the $\ln$ (AUC ratio) and $\ln \left(\mathrm{C}_{\max }\right.$ ratio) using $\mathrm{JMP}^{\circ}$ Pro 13.1.0 (SAS Institute Inc., Cary, NC, USA), which is a statistical analysis software, based on the collected information.

The magnitudes of the effects of food were classified based on the reported pharmacokinetic differences between the fed and fasted states. With regard to the AUC ratio, food effects were classified into 3 groups, the absorption increase group (AUC ratio > 1.25), the absorption invariant group $(0.8 \leq \mathrm{AUC}$ ratio $\leq 1.25)$, and the absorption decrease group (AUC ratio $<0.8$ ), in accordance with the variations in bioequivalence in the guidelines for bioequivalence studies of generic products (0.8-1.25) [16]. The $\mathrm{T}_{\max }$ ratios were classified into 3 groups, the absorption time prolongation group $\left(\mathrm{T}_{\max }\right.$ ratio $>2.0)$, the absorption time invariant group $(0.5 \leq$ $\mathrm{T}_{\max }$ ratio $\left.\leq 2.0\right)$, and the absorption time shortening group $\left(\mathrm{T}_{\max }\right.$ ratio $\left.<0.5\right)$.

\section{In silico prediction of the physicochemical properties of oral antineoplastic drugs}

We predicted the following physicochemical properties from the 2D chemical structures of antineoplastic drugs by a prediction model using artificial neural network technology: octanol/water partition coefficient $(\log \mathrm{P})$; solubility in fasted-state simulated gastric fluid (FaSSGF), fasted-state simulated intestinal fluid (FaSSIF) and fedstate simulated intestinal fluid (FeSSIF) [17, 18]; and nonionized fraction at $\mathrm{pH} 6.8\left(\right.$ FUnion $\left._{6.8}\right)$ and $\mathrm{pH} 1.2$ $\left(\right.$ FUnion $\left._{1.2}\right)$. These predictions were made using ADMET Predictor $^{\text {rm }} 8.1$ (Simulation Plus, Inc., Lancaster, CA, USA), which is an ADMET physicochemical properties prediction software. For the accuracy of the $\log \mathrm{P}$ predictions, the root mean square error (RMSE) was $0.314 \log$ units, the mean absolute error (MAE) was $0.241 \log$ units, and the $R^{2}$ value was 0.971 .

\begin{tabular}{ll} 
Table $\mathbf{1}$ Usages in package inserts of oral & antineoplastic drugs \\
\hline Usage & Number of compounds \\
\hline fasting & 15 \\
postprandial & 15 \\
before bedtime & 1 \\
certain conditions & 2 \\
unspecified & 39 \\
total & 72 \\
\hline
\end{tabular}

a) In addition to what is specified in the package inserts, conditions described in the precautions such as "avoid taking from $1 \mathrm{~h}$ before meal until $2 \mathrm{~h}$ after meal", "avoid taking $1 \mathrm{~h}$ before and after meal" or "avoid taking from $1 \mathrm{~h}$ before meal until $2 \mathrm{~h}$ after meal when taking high fat meals" are also classified as "fasting" 


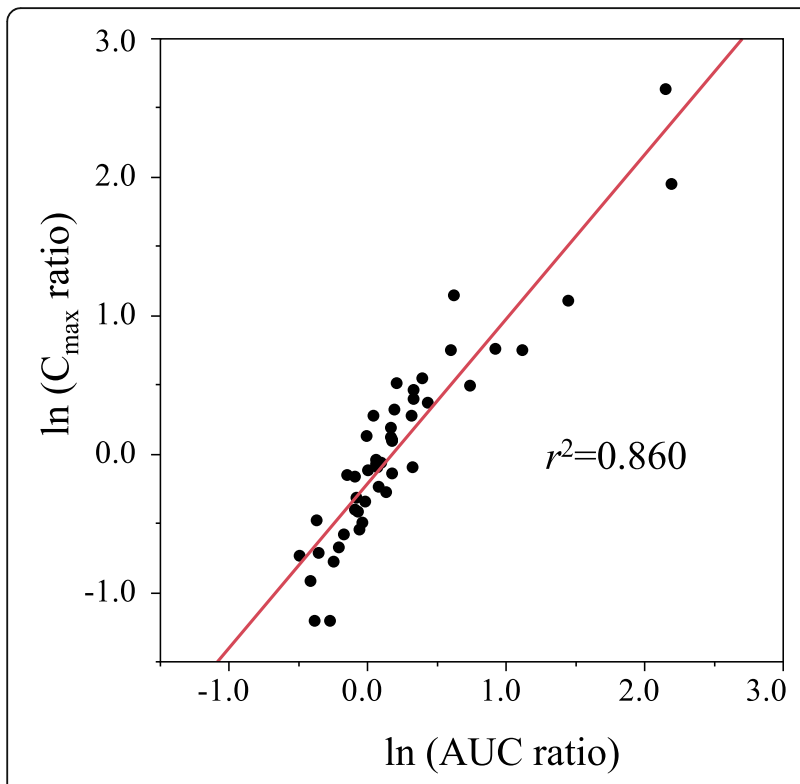

Fig. 1 Bivariate relationship between In (AUC ratio) and In $\left(C_{\max }\right.$ ratio $)$
We analyzed the relationship between the known effects of food and physicochemical properties using JMP ${ }^{\circ}$ Pro 13.1.0. We analyzed the bivariate relationship using AUC changes (AUC increase, invariance and decrease) as objective variables and $\log \mathrm{P}$ and the solubility in FaSSGF, FaSSIF and FeSSIF as explanatory variables and compared the medians for all pairs using Steel-Dwass test. Similarly, we analyzed the bivariate relationship based on $T_{\max }$ changes ( $T_{\max }$ prolongation, invariance and shortening) as objective variables and $\log \mathrm{P}$ and the solubility in FaSSGF, FaSSIF, FeSSIF and FaSSIF/FeSSIF solubility ratio as explanatory variables and compared the averages using Welch's test.

Based on the results of the analysis, a decision tree analysis was performed with the changes in AUC as the objective variables and $\log \mathrm{P}$ as the explanatory variable. The criterion function by which nodes are split is the LogWorth statistic [LogWorth $=(-1) * \ln$ (chi-squared $p$-value)], which is to be maximized. The division point of $\log \mathrm{P}$ related to the increase in drug absorption by food was obtained. Furthermore, we predicted whether the absorption would increase for drugs for which the effects of food are unknown.

Table 2 Oral antineoplastic drugs for which absorption is changed by food

\begin{tabular}{|c|c|c|c|c|c|c|c|c|c|c|}
\hline Absorption & Generic name & $\begin{array}{l}\text { Molecular } \\
\text { weight }\end{array}$ & Usage & $\begin{array}{l}\text { AUC } \\
\text { ratio }\end{array}$ & $\begin{array}{l}C_{\max } \\
\text { ratio }\end{array}$ & $\begin{array}{l}T_{\max } \\
\text { ratio }\end{array}$ & $\log P$ & InFaSSGF & InFaSSIF & InFeSSIF \\
\hline \multirow{14}{*}{$\begin{array}{l}\text { absorption } \\
\text { increase }\end{array}$} & bexarotene & 348.48 & postprandial & 8.96 & 7.04 & - & 7.46 & -8.28 & -4.71 & -1.02 \\
\hline & abiraterone acetate & 391.55 & fasting & 8.59 & 13.97 & 1.00 & 5.40 & -6.91 & -4.71 & -2.16 \\
\hline & lapatinib tosylate hydrate & 943.49 & fasting & 4.25 & 3.03 & 2.53 & 5.18 & -4.71 & -5.81 & -4.83 \\
\hline & vemurafenib & 489.93 & fasting & 3.05 & 2.12 & 1.88 & 5.17 & -3.82 & -4.02 & -2.56 \\
\hline & pazopanib hydrochloride & 473.98 & fasting & 2.51 & 2.14 & 1.51 & 3.46 & -0.77 & -5.30 & -2.50 \\
\hline & erlotinib hydrochloride & 429.90 & fasting & 2.09 & 1.64 & 1.04 & 3.13 & -1.70 & -5.81 & -2.15 \\
\hline & ibrutinib & 440.50 & not mentioned & 1.86 & 3.15 & - & 2.87 & -3.38 & -3.65 & -2.98 \\
\hline & $\begin{array}{l}\text { nilotinib hydrochloride } \\
\text { hydrate }\end{array}$ & 584.00 & fasting & 1.82 & 2.12 & 1.25 & 5.01 & -4.02 & -6.21 & -2.49 \\
\hline & ceritinib & 558.14 & fasting & 1.54 & 1.45 & 1.33 & 6.08 & -4.96 & -4.96 & -2.15 \\
\hline & regorafenib hydrate & 500.84 & postprandial & 1.48 & 1.73 & 1.5 & 5.30 & -5.30 & -4.51 & -2.45 \\
\hline & exemestane & 296.41 & postprandial & 1.39 & 1.59 & 1.94 & 3.13 & -2.85 & -2.75 & -2.40 \\
\hline & bosutinib hydrate & 548.47 & postprandial & 1.39 & 1.49 & 1.00 & 4.94 & 1.62 & -4.61 & -4.51 \\
\hline & vorinostat & 264.32 & postprandial & 1.38 & 0.91 & 2.67 & 1.59 & -0.93 & -0.028 & -1.37 \\
\hline & gefitinib & 446.91 & postprandial & 1.37 & 1.32 & - & 4.34 & 0.34 & -4.42 & -2.75 \\
\hline \multirow[t]{7}{*}{$\begin{array}{l}\text { absorption } \\
\text { decrease }\end{array}$} & everolimus & 958.24 & $\begin{array}{l}\text { certain } \\
\text { conditions }\end{array}$ & 0.78 & 0.46 & 2.50 & 5.56 & -6.91 & -4.96 & -0.71 \\
\hline & $\begin{array}{l}\text { trametinib dimethyl } \\
\text { sulfoxide }\end{array}$ & 693.53 & fasting & 0.76 & 0.30 & 2.69 & 2.84 & -5.52 & -3.30 & -2.33 \\
\hline & dabrafenib mesylate & 615.67 & fasting & 0.70 & 0.49 & 3.00 & 4.71 & -4.34 & -4.96 & -1.08 \\
\hline & sorafenib tosylate & 637.03 & fasting & 0.69 & 0.62 & 1.00 & 5.07 & -4.96 & -4.27 & -2.47 \\
\hline & ixazomib citrate & 517.13 & fasting & 0.68 & 0.30 & 3.92 & 1.53 & -5.12 & 0.30 & -0.15 \\
\hline & capecitabine & 359.35 & postprandial & 0.66 & 0.40 & 2.00 & 1.28 & -0.068 & -2.28 & -0.042 \\
\hline & afatinib maleate & 718.09 & fasting & 0.61 & 0.48 & 2.28 & 4.05 & 0.31 & -3.41 & -2.03 \\
\hline
\end{tabular}




\section{Results}

\section{Effects of food on the pharmacokinetics of oral} antineoplastic drugs

Information on effects of food on the pharmacokinetics of 48 compounds (66.7\%) out of the 72 investigated oral antineoplastic drugs was obtained. There were 30 compounds for which dietary conditions were defined in the usages or the precautions described in the package inserts; 15 compounds required postprandial administration, and the other 15 compounds required fasting administration (Table 1). The medians (maximum, minimum) of the AUC ratios, $\mathrm{C}_{\max }$ ratios and $\mathrm{T}_{\max }$ ratios were $1.08(8.96,0.61), 0.94$ (13.97, $0.30)$ and $1.91(3.92,0.50)$, respectively. There was a positive correlation between $\ln$ (AUC ratio) and $\ln$ $\left(C_{\max }\right.$ ratio) $\left(r^{2}=0.86\right)$ (Fig. 1).
Classification based on the type of the effect of food based on the AUC ratio resulted in 14 compounds in the absorption increase group, $26 \mathrm{com}$ pounds in the absorption invariant group, and 7 compounds in the absorption decrease group. Classification based on the $\mathrm{T}_{\max }$ ratio resulted in $15 \mathrm{com}$ pounds in the absorption time prolongation group, 23 compounds in the absorption time invariant group, and no compounds in the absorption time shortening group. The compounds in the absorption increase group and absorption decrease group are shown in Table 2. The AUC increased by a factor of 8 or more due to food in the cases of bexarotene and abiraterone acetate. On the other hand, AUC decreased by approximately $60 \%$ due to food in the cases of capecitabine and afatinib.
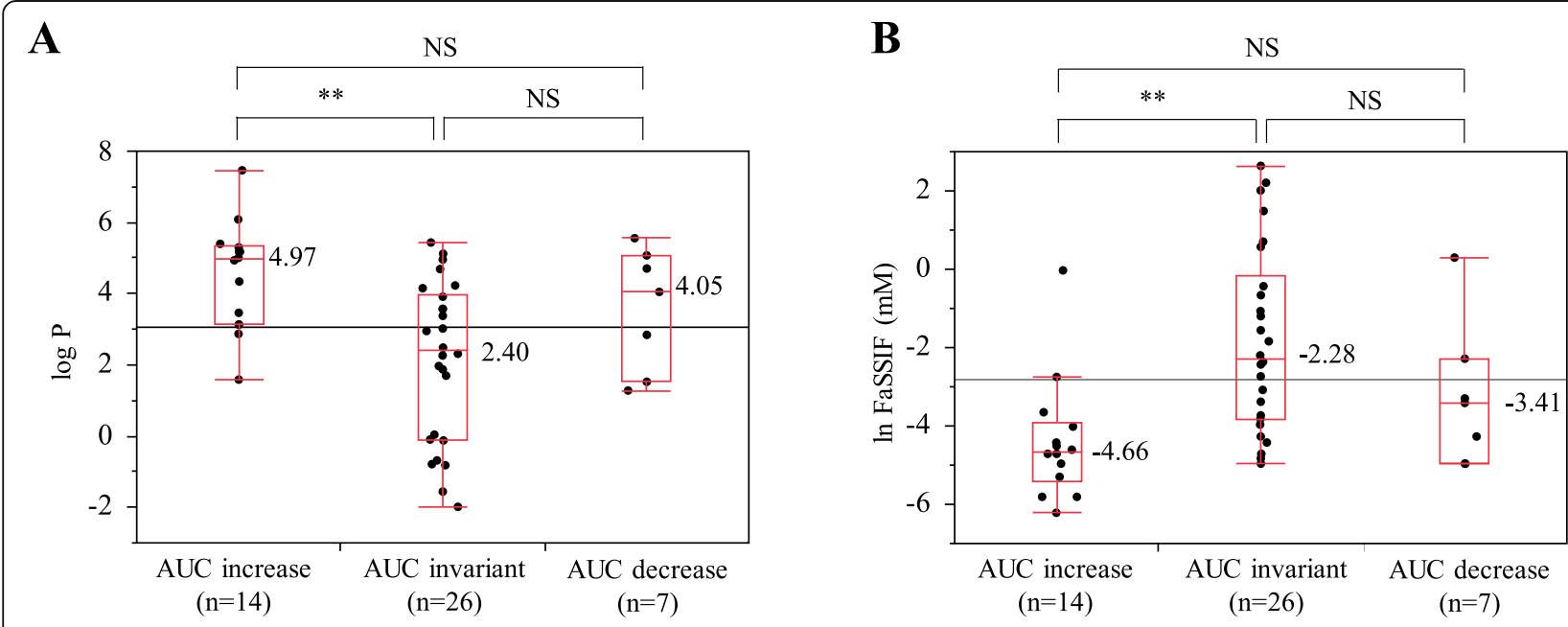

$\mathbf{C}$

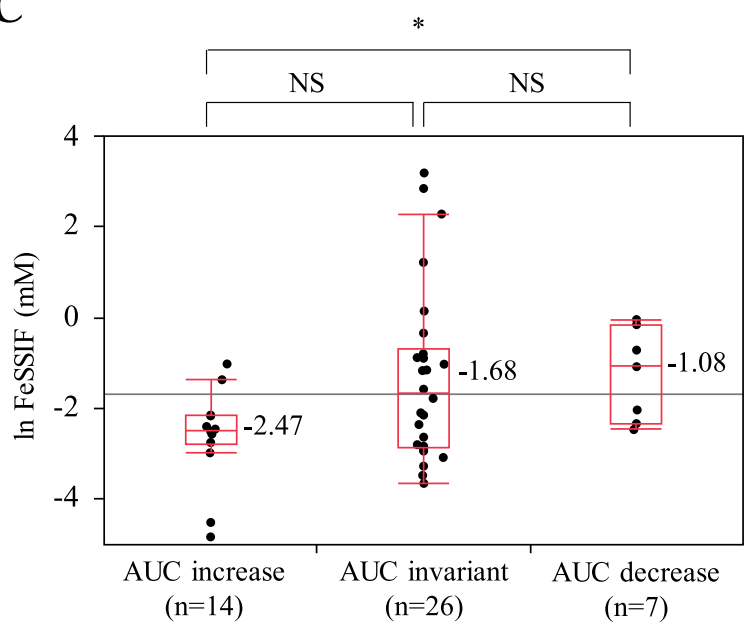

D

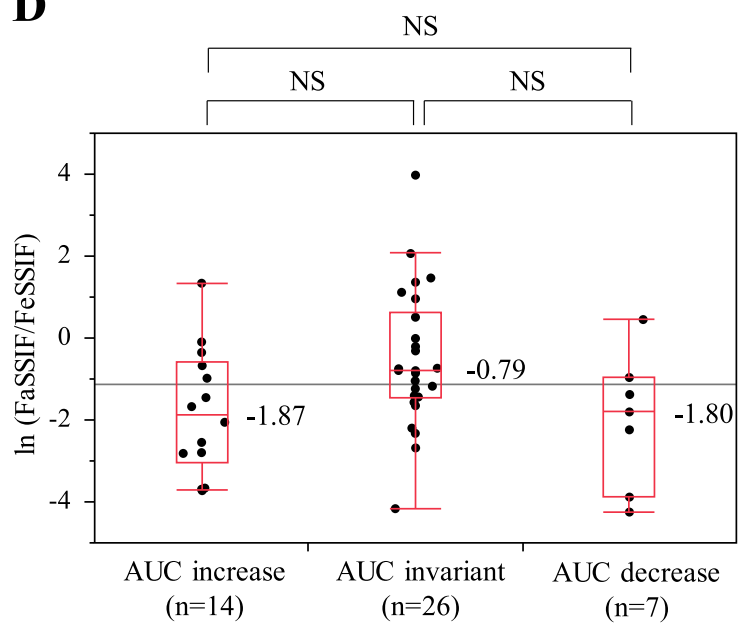

Fig. 2 Relationship between the known food effects and physicochemical properties obtained by in silico predictions. a Relationship between AUC changes and logP. b Relationship between AUC changes and the solubility in FaSSIF. cRelationship between AUC changes and the solubility in FeSSIF. $\mathbf{d}$ Relationship between AUC changes and FaSSIF/FeSSIF solubility ratio. Steel-Dwass test. ${ }^{*}: P<0.01$. *:P $<0.05$. NS: not significant 
In silico prediction of the physicochemical properties of oral antineoplastic drugs

Using JMP ${ }^{\odot}$ Pro 13.1.0., we analyzed the relationship between the reported effects of food and the physicochemical properties obtained from in silico predictions. The bivariate relationship was analyzed using AUC changes as the objective variables and $\log \mathrm{P}$ as the explanatory variable. The medians of the $\log \mathrm{P}$ value (maximum, minimum) were 4.97 $(7.46,1.59)$ in the AUC increase group, $2.40(5.44,-1.99)$ in the AUC invariant group, and $4.05(5.56,1.28)$ in the AUC decrease group. The median in the AUC increase group was significantly higher than that of the AUC invariant group $(P=0.0054)$ (Fig. 2a). In the bivariate analysis of AUC changes and solubility in FaSSIF, the median of lnFaSSIF was -4.66 in the AUC increase group, -2.28 in the AUC invariant group and -3.41 in the AUC decrease group. The median in the AUC increase group was significantly low than that of the AUC invariant group $(P=0.0013)$ (Fig. $2 b)$. Similarly, in FeSSIF, the median of lnFeSSIF in the AUC increase group was lower than that of the AUC invariant group, although the difference was not significant (Fig. 2c). In the bivariate analysis of the changes in $\mathrm{T}_{\max }$ and solubility in FaSSIF, the median of $\operatorname{lnFaSSIF}$ was -1.88 in the $\mathrm{T}_{\max }$ prolongation group and -4.27 in the $T_{\max }$ invariant group (Fig. 3). The median in the $\mathrm{T}_{\max }$ prolongation group was significantly higher than that of the $\mathrm{T}_{\max }$ invariant group $(P=0.0129)$, and a similar trend was observed for FeSSIF. However, no significant difference was observed between the $\mathrm{T}_{\max }$ prolongation group and the $\mathrm{T}_{\max }$ invariant group in the bivariate analysis of the changes in $\mathrm{T}_{\max }$ and $\log \mathrm{P}$. As described above, we found that compounds for which the

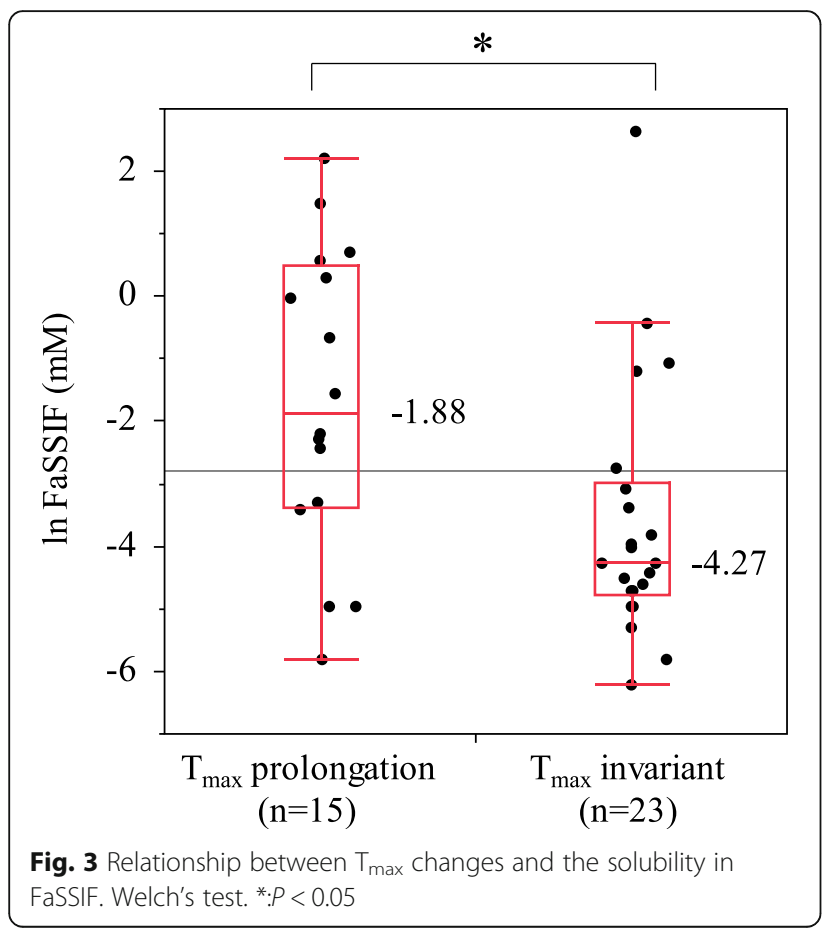

absorption was increased by food had higher $\log \mathrm{P}$ and lower solubilities in FaSSIF and FeSSIF and that compounds for which the absorption was decreased had higher solubilities in FaSSIF. On the other hand, no relationship between the effects of food and other physicochemical properties, such as the nonionized fraction, were observed.

Since a correlation was found between increased absorption by food and the values of $\log \mathrm{P}$, the decision tree analysis was performed with AUC changes as the objective variables and $\log \mathrm{P}$ as the explanatory variable. The division point of $\log \mathrm{P}$ related to the increase in drug absorption by food was obtained (Table 3). As a result, the division point of $\log \mathrm{P}$ was 4.34 , and it was classified as AUC invariant with $\log \mathrm{P}<4.34$ and as AUC increase with $\log \mathrm{P} \geq 4.34$ (the true rate was $77.5 \%$ ). The falsepositive rate and the false-negative rate were 15.4 and $35.7 \%$, respectively. Furthermore, we found that an AUC increase due to food did not occur with compounds with lower lipophilicities $(\log P<1.59)$. Based on these results, we were able to predict whether the absorption would increase for 24 compounds for which the effects of food are unknown (Table 4). We predicted that the risk of absorption increase due to food was high for 7 compounds with $\log \mathrm{P} \geq 4.34$. All of these compounds had lower FaSSIF solubilities and were consistent with the characteristics of compounds for which the absorption was increased by food. On the other hand, we inferred that an absorption increase would not occur with 13 compounds with $\log \mathrm{P}<1.59$. These compounds tended to show higher FaSSIF solubilities relative to compounds with $\log \mathrm{P} \geq 4.34$.

\section{Discussion}

In this study, we analyzed variables correlated with the AUC ratio out of physicochemical properties obtained by in silico predictions, and it was suggested that drugs with high lipophilicities ( $\log \mathrm{P}$ values) and low intestinal solubilities (in FaSSIF and FeSSIF) had high risks of absorption increases due to food. This result is considered to be due to the solubility increase caused by the promotion of bile secretion by food [19]. Since the majority of tyrosine kinase inhibitors (TKIs) are substrates for drug transporters (e.g. ABCB1 and ABCG2) [7, 20], food may also inhibit drug transporters, thereby increasing drug absorption [10]. On the other hand, we predicted that

Table 3 Decision tree analysis using AUC changes as objective variables and $\log P$ as the explanatory variable

\begin{tabular}{lll}
\hline & AUC increase & AUC invariant \\
\hline $\log P \geq 4.34$ & 9 & 4 \\
$4.34>\log P \geq 1.59$ & 5 & 14 \\
$1.59>\log P$ & 0 & 8 \\
\hline
\end{tabular}


Table 4 Prediction of absorption changes in oral antineoplastic drugs for which the food effects are unknown

\begin{tabular}{|c|c|c|c|c|c|c|}
\hline Prediction & Generic name & Usage & $\log P$ & InFaSSGF & InFaSSIF & InFeSSIF \\
\hline \multirow{7}{*}{$\begin{array}{l}\text { absorption } \\
\text { increase } \\
\text { (logP } \geq 4.34)\end{array}$} & toremifene citrate & - & 6.73 & -2.23 & -4.34 & -0.73 \\
\hline & tamoxifen citrate & - & 6.64 & -2.11 & -4.20 & -0.58 \\
\hline & tretinoin & postprandial & 6.07 & -6.91 & -3.44 & -1.13 \\
\hline & mitotane & - & 6.06 & -6.91 & -4.42 & -1.06 \\
\hline & mepitiostane & - & 6.01 & -7.83 & -4.51 & -2.56 \\
\hline & tamibarotene & postprandial & 5.80 & -5.81 & -3.06 & -1.13 \\
\hline & cytarabine ocfosphate hydrate & postprandial & 4.56 & -4.02 & -5.81 & -5.81 \\
\hline \multirow[t]{4}{*}{ no prediction } & medroxyprogesterone acetate & - & 3.94 & -5.30 & -4.27 & -2.59 \\
\hline & estramustine phosphate sodium hydrate & - & 3.92 & -3.30 & -1.20 & -1.56 \\
\hline & flutamide & postprandial & 2.90 & -2.69 & -2.15 & -1.72 \\
\hline & anastrozole & - & 2.67 & -2.90 & -3.54 & -1.48 \\
\hline \multirow{13}{*}{$\begin{array}{l}\text { absorption } \\
\text { invariant } \\
(\log P<1.59)\end{array}$} & cyclophosphamide hydrate & - & 0.77 & 2.47 & 1.96 & 2.84 \\
\hline & etoposide & - & 0.76 & -2.00 & -1.80 & -1.51 \\
\hline & sobuzoxane & - & 0.46 & -0.11 & -3.04 & -1.94 \\
\hline & tegafur & - & -0.12 & 1.35 & 1.49 & 2.28 \\
\hline & tegafur/gimeracil/oteracil potassium & postprandial & -0.12 & 1.35 & 1.49 & 2.28 \\
\hline & melphalan & - & -0.34 & 2.27 & 1.29 & 0.77 \\
\hline & mercaptopurine hydrate & - & -0.52 & 0.91 & -1.14 & -0.46 \\
\hline & fluorouracil & - & -0.81 & 1.49 & 1.66 & 2.67 \\
\hline & busulfan & - & -0.81 & 3.35 & 7.89 & 5.01 \\
\hline & doxifluridine & - & -1.08 & 2.50 & 3.57 & 3.36 \\
\hline & methotrexate & - & -1.11 & 3.02 & 1.06 & -1.86 \\
\hline & hydroxycarbamide & - & -1.66 & 3.90 & 3.74 & 3.12 \\
\hline & ubenimex & - & -1.67 & 3.33 & 2.26 & 1.72 \\
\hline
\end{tabular}

an absorption increase would not occur for the compounds with high water solubilities. In the case of drugs with high intestinal solubility, there are risks of delaying the absorption rate.

In the decision tree analysis, the division point of $\log \mathrm{P}$ related to increased drug absorption by food was calculated as 4.34. In support of this finding, a previous study that predicted the effects of fed-state intestinal contents on drug dissolution showed that hydrophobic drugs with $\log \mathrm{P}>4$ showed a significant increase in solubility in FeSSIF [18]. It was also reported that increase of solubilization by bile acids would not occur in drugs with a $\log \mathrm{P}<2[3,21]$. When the division point of $\log \mathrm{P}$ was $4.34,64 \%$ (9 out of 14 ) of true positives (AUC increase) could be accurately predicted, while $36 \%$ were predicted as false negatives. In other words, $\log \mathrm{P} \geq 4.34$ provides a high likehood of being an AUC increase drugs, whereas $36 \%$ of AUC increase drugs have the properties with $\log \mathrm{P}<4.34$. Total 85\% (22 out of 26) of true negatives (AUC invariant) could be accurately predicted, while only $15 \%$ were predicted as false positives. That means that AUC invariant drugs are almost in $\log \mathrm{P}<4.34$.
Based on the literature results, we found that the usages described in the package inserts in most drugs for which the absorption increased or decreased due to food were defined as postprandial administration, fasting administration, or other specific conditions. On the other hand, for the drugs for which no clinical trial data on the effects of food are available, 7 compounds were predicted to have risks of absorption increases by decision tree analysis, and meal conditions were defined in the usages in the package inserts for only 3 of these compounds. Since the absorption may be increased by food in drugs with $\log \mathrm{P} \geq 4.34$, food effects should be considered even in the cases of drugs that have no clinical trial data on food effects. In this study, we focused on the pharmacokinetic changes caused by food in oral antineoplastic drugs and evaluate their relevance to $\log \mathrm{P}$ values. A $\log \mathrm{P}$ value, which indicates lipophilicity, is a frequently used parameter in correlation with membrane permeability [22-25] and is a popular index for Japanese pharmacists. The $\log \mathrm{P}$ value of each antineoplastic drug is easily available on the drug package insert, and is easy to evaluate for pharmacist. The BCS classification has been used to evaluate food-drug interactions in the development stage of pharmaceuticals 
[26, 27], however, the index is not popular among clinical pharmacists in Japan to date. Additionally, the identification of "highly soluble" and "highly permeable" for BCS are not simple [26, 27]. Therefore, we believe that the simple prediction of drug-food interaction by the $\log \mathrm{P}$ values obtained from the results of this study is useful for clinical pharmacists.

In this study, we found significant differences between compounds with food-induced absorption increases and food-invariant absorption, and between those with foodinduced absorption time prolongation and foodinvariant absorption times. In addition, we found some common trends in these compounds based on their structures. There was no significant difference between the compounds for which the absorption is decreased by food and those for which the absorption is increased or invariant. Although their molecular weights tend to be large, there were only 7 compounds for which absorption decreased due to food, making it difficult to conduct further evaluations. Additionally, further evaluation of the relationship between food and the physicochemical properties is required because drug administration tests are not performed under the same conditions and the contents of the meal ingested can vary. It is difficult to verify our predictions in clinical trials, we are trying to build a more accurate in slico classification model, using an artificial neural network (ANN) as an alternative method to verify our predictions.

\section{Conclusion}

In this study, we found that the antineoplastic drugs for which absorption increases or does not change due to food can be generally predicted by their $\log \mathrm{P}$ values. This suggests that we should implement pharmaceutical management with regard to meals and the timing of administration using $\log \mathrm{P}$ as an index and considering the characteristics of drugs such as the narrowness of their therapeutic and toxic ranges.

\section{Abbreviations}

2D: Two-dimensional; AUC: Area under the curve of the drug concentrationtime profile; $C_{\text {max }}$ : Maximum serum concentration; FaSSGF: Fasted-state simulated gastric fluid; FaSSIF: Fasted-state simulated intestinal fluid; FeSSIF: Fed-state simulated intestinal fluid; logP: Partition coefficient; MAE: Mean absolute error; RMSE: Root mean square error; $T_{\text {max }}$ : The time at which $C_{\max }$ is observed

\section{Acknowledgements}

We are grateful to Ms. T. Maeshima for helpful discussions and comments on the manuscript.

\section{Authors' contributions}

Fl conceived the study and designed the protocol. FO drafted the manuscript. MK and FO analyzed and interpreted the data. MW helped draft the manuscript. All authors edited the manuscript and approved the final version.

\section{Funding}

This study was supported by research funds from Teikyo University.

\section{Availability of data and materials}

All data generated or analyzed during this study are included in this published article.

\section{Ethics approval and consent to participate}

Not applicable.

\section{Consent for publication}

Not applicable.

\section{Competing interests}

The authors declare that they have no competing interests.

\section{Author details}

${ }^{1}$ Department of Clinical \& Pharmaceutical Sciences, Faculty of Pharma Science, Teikyo University, 2-11-1, Kaga, Itabashi-ku, Tokyo 173-8605, Japan. ${ }^{2}$ Department of Medical \& Pharmaceutical Sceinces, Faculty of Pharma Science, Teikyo University, 2-11-1, Kaga, Itabashi-ku, Tokyo 173-8605, Japan.

Received: 11 March 2019 Accepted: 12 November 2019

Published online: 03 December 2019

\section{References}

1. Peter G. Welling. Influence of food and diet on gastrointestinal drug absorption. J Pharmacokinet Biopharm. 1977;5:291-334.

2. Pater G. Welling.Effect of food on drug absorption. Pharmac Ther. 1989;43: 425-41.

3. van de Waterbeemd H, Testa B, Mannhold R, Kubinyi H, Folkers G. Drug bioavailability: estimation of solubility, permeability, absorption and bioavailability. Weinheim: Wiley-VCH GmbH \& Co.; 2009. p. 523-58.

4. Devriese LA, Koch KM, Mergui-Roelvink M, Matthys GM, Ma WW, Robidoux A, Stephenson JJ, Chu QS, Orford KW, Cartee L, Botbyl J, Arya N, Schellens $J \mathrm{H}$. Effects of low-fat and high-fat meals on steady-state pharmacokinetics of lapatinib in patients with advanced solid tumours. Investig New Drugs. 2014;32:481-8.

5. Amidon GL, Lennernäs $H$, Shah VP, Crison JR. A theoretical basis for a biopharmaceutic drug classification: the correlation of in vitro drugproduct dissolution and in vivo bioavailability. Pharm Res. 1995;12:413-20.

6. Fleisher D, Li C, Zhou Y, Pao LH, Karim A. Drug, meal and formulation interactions influencing drug absorption after oral administration. Clinical implications. Clin Pharmacokinet. 1999;36:233-54.

7. Wu CY, Benet LZ. Predicting drug disposition via application of BCS: transport/absorption/elimination interplay and development of a biopharmaceutics drug disposition classification system. Pharm Res. 2005;22:11-23.

8. Gu CH, Li H, Levons J, Lentz K, Gandhi RB, Raghavan K, Smith RL. Predicting effect of food on extent of drug absorption based on physicochemical properties. Pharm Res. 2007:24:1118-30.

9. List of Approved Products. PMDA,Tokyo, 2019. https://www.pmda.go.jp/ english/review-services/reviews/approved-information/drugs/0002.html. Accessed 3 Sept 2019.

10. Parsad S, Ratain MJ. Food effect studies for oncology drug products. Clin Pharmacol Ther. 2017;101:606-12.

11. Urabe A, Shimada K, Kawai S. Today's drug therapy in 2018. Tokyo: Nankodo Co. Ltd; 2018. p. 183. [in Japanese]

12. Singh BN, Malhotra BK. Effects of food on the clinical pharmacokinetics of anticancer agents. Clin Pharmacokinet. 2004;43:1127-56.

13. Jain RK, Brar SS, Lesko LJ. Food and Oral Antineoplastics: more than meets the eye. Clin Cancer Res. 2010;16:4305-7.

14. Ruggiero A, Cefalo MG, Coccia P, Mastrangelo S, Maurizi P, Riccardi R. The role of diet on the clinical pharmacology of oral antineoplastic agents. Eur J Clin Pharmacol. 2012;68:115-22.

15. Drug inserts, interview forms, and examination reports of each oral antineoplastic drugs. [in Japanese] http://www.pmda.go.jp/PmdaSearch/ iyakuSearch/ Accessed 3 Sept 2019.

16. Guideline for bioequivalence studies of generic products. PMDA,Tokyo, 2012 [in Japanese] https://www.pmda.go.jp/files/000160026.pdf Accessed 3 Sept 2019.

17. Jantratid E, Janssen N, Reppas C, Dressman JB. Dissolution media simulating conditions in the proximal human gastrointestinal tract: an update. Pharm Res. 2008;25:1663-75. 
18. Gamsiz ED, Ashtikar M, Crison J, Woltosz W, Bolger MB, Carrier RL. Predicting the effect of fed-state intestinal contents on drug dissolution. Pharm Res. 2010;27:264.

19. Charman WN, Porter CJ, Mithani S, Dressman JB. Physiochemical and physiological mechanisms for the effects of food on drug absorption: the role of lipids and pH. J Pharm Sci. 1997;86:269-82.

20. Widmer N, Bardin C, Chatelut E, Paci A, Beijnen J, Levêque D, Veal G, Astier A. Review of therapeutic drug monitoring of anticancer drugs part two-targeted therapies. Eur J Cancer. 2014;50:2020-36.

21. Mithani SD, Bakatselou V, TenHoor CN, Dressman JB. Estimation of the increase in solubility of drugs as a function of bile salt concentration. Pharm Res. 1996;13:163-7.

22. Lipinski CA, Lombardo F, Dominy BW, Feeney PJ. Experimental and computational approaches to estimate solubility and permeability in drug discovery and development settings. Adv Drug Deliv Rev. 2001:46:3-26.

23. Winiwarter $S$, Bonham NM, Ax F, Hallberg A, Lennernäs $H$, Karlén A. Correlation of human jejunal permeability (in vivo) of drugs with experimentally and theoretically.Derived parameters. A multivariate data analysis approach. J Med Chem. 1998;41:4939-49.

24. Artursson P, Karlsson J. Correlation between oral drug absorption in humans and apparent drug permeability coefficients in human intestinal epithelial (Caco-2) cells. Biochem Biophys Res Commun. 1991;175:880-5.

25. Takagi T, Ramachandran C, Bermejo M, Yamashita S, Yu LX, Amidon GL. A provisional biopharmaceutical classification of the top 200 oral drug products in the United States, Great Britain, Spain, and Japan. Mol Pharm. 2006;:631-43

26. ICH harmonised guideline Biopharmaceutics Classification System-Based Biowaivers M9, Draft version Endorsed on 7 June 2018, https://www.ich.org/ fileadmin/Public_Web_Site/ICH_Products/Guidelines/Multidisciplinary/M9/ M9EWG_DraftGuideline_Step2_2018_0606.pdf.

27. Heimbach T, Xia B, Lin TH, He H. Case studies for practical food effect assessments across BCS/BDDCS class compounds using in silico, in vitro, and preclinical in vivo data. AAPS J. 2013;15:143-58.

\section{Publisher's Note}

Springer Nature remains neutral with regard to jurisdictional claims in published maps and institutional affiliations.

Ready to submit your research? Choose BMC and benefit from:

- fast, convenient online submission

- thorough peer review by experienced researchers in your field

- rapid publication on acceptance

- support for research data, including large and complex data types

- gold Open Access which fosters wider collaboration and increased citations

- maximum visibility for your research: over $100 \mathrm{M}$ website views per year

At $\mathrm{BMC}$, research is always in progress.

Learn more biomedcentral.com/submissions 